\title{
A high-frequency non-resonant elliptical vibration-assisted cutting device for diamond turning microstructured surfaces
}

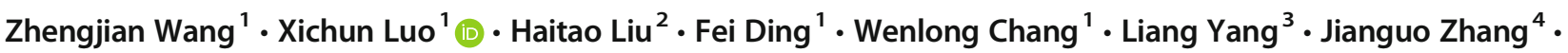 \\ Andrew Cox ${ }^{5}$
}

Received: 17 October 2020 / Accepted: 3 January 2021 / Published online: 15 January 2021

(C) The Author(s) 2021

\begin{abstract}
In recent years, research has begun to focus on the development of non-resonant elliptical vibration-assisted cutting (EVC) devices, because this technique offers good flexibility in manufacturing a wide range of periodic microstructures with different wavelengths and heights. However, existing non-resonant EVC devices for diamond turning can only operate at relatively low frequencies, which limits their machining efficiencies and attainable microstructures. This paper concerns the design and performance analysis of a non-resonant EVC device to overcome the challenge of low operational frequency. The structural design of the non-resonant EVC device was proposed, adopting the leaf spring flexure hinge (LSFH) and notch hinge prismatic joint (NHPJ) to mitigate the cross-axis coupling of the reciprocating displacements of the diamond tool and to combine them into an elliptical trajectory. Finite element analysis (FEA) using the mapped meshing method was performed to assist the determination of the key dimensional parameters of the flexure hinges in achieving high operational frequency while considering the cross-axis coupling and modal characteristics. The impact of the thickness of the LSFH on the sequence of the vibrational mode shape for the non-resonant EVC device was also quantitatively revealed in this study. Moreover, a reduction in the thickness of the LSFH can reduce the natural frequency of the non-resonant EVC device, thereby influencing the upper limit of its operational frequency. It was also found that a decrease in the neck thickness of the NHPJ can reduce the coupling ratio. Experimental tests were conducted to systematically evaluate the heat generation, cross-axis coupling, modal characteristics and diamond tool's elliptical trajectory of a prototype of the designed device. The test results showed that it could operate at a high frequency of up to $5 \mathrm{kHz}$. The cross-axis coupling ratio and heat generation of the prototype are both at an acceptable level. The machining flexibility and accuracy of the device in generating microstructures of different wavelengths and heights through tuning operational frequency and input voltage have also been demonstrated via manufacturing the micro-dimple arrays and two-tier microstructured surfaces. High-precision microstructures were obtained with $1.26 \%$ and $10.67 \%$ machining errors in wavelength and height, respectively.
\end{abstract}

Keywords Microstructured surfaces $\cdot$ Elliptical vibration-assisted cutting $\cdot$ Non-resonant $\cdot$ Diamond turning

Xichun Luo

xichun.luo@strath.ac.uk

1 Centre for Precision Manufacturing, DMEM, University of Strathclyde, Glasgow G1 1XJ, UK

2 School of Mechatronics Engineering, Harbin Institute of Technology, Harbin 150001, China

3 School of Mechanical Engineering, Dalian Jiaotong University, Dalian 116028, China

4 School of Mechanical Science and Engineering, Huazhong University of Science \& Technology, Wuhan 430063, China

5 Contour Fine Tooling Ltd., Stevenage SG1 4QR, UK

\section{Introduction}

In the engineering field, the demand for microstructured surfaces with tailored physical, chemical and mechanical properties has recently increased dramatically [1-3]. In tribology, for instance, certain microstructured surfaces not only reduce friction [4-6] but also shorten the running-in period of automobile engines and extend their lifetime [7].

Manufacturing technologies such as laser beam machining (LBM), electrical discharge machining (EDM), focused ion beam (FIB) machining, lithography, chemical etching and vibration-assisted diamond cutting have been adopted to obtain microstructured surfaces. Both LBM and EDM use 
thermal energy to remove material, but EDM mainly compliments electrically conductive materials, which hinder its widespread use. In addition to its high capital cost and low metal removal rate, it is difficult to machine highly reflective and transparent materials by LBM $[8,9]$. FIB machining can be applied to the manufacturing of tailored structures on the order of tens of nanometres [10,11]; however, FIB is not industrial viable due to its extremely low material removal rate [12]. The surface finish attainable by lithography and chemical etching is usually low (in several microns) and neither approach is eco-friendly [13].

Shamoto and Moriwaki [14] first developed the elliptical vibration-assisted cutting (EVC) technique that can be used to mitigate the problem of diamond tool's chemical wear while machining ferrous metals $[15,16]$. Meanwhile, this technique has also been applied by many researchers to manufacture microstructures [17-19], nanostructures [20] and hybrid micro/nanostructures [21]. Compared with conventional diamond cutting, the intermittent tool/workpiece contact endows the elliptical vibration-assisted diamond cutting technique with not only a surface-texturing ability but also chipbreaking [22] and burr-suppression [23] features. It can, therefore, obtain both precision and ultra-precision parts with high efficiency and low environmental impact [24]. In this approach, the attainable wavelengths and heights of periodical microstructures are determined by the operational frequencies and input voltages for the EVC device.

Based on the operational frequency mode, EVC can be classified into two types: resonant mode and non-resonant mode. Resonant EVC vibrators can obtain ultrasonic operational frequency $[25,26]$ and large vibration amplitude over tens of micrometres [27] as a result of the high energy efficiency of the resonant mode. However, resonant EVC devices can only work under a fixed frequency (i.e., resonant frequency) and therefore can only machine microstructures with a fixed wavelength and height $[28,29]$. By contrast, nonresonant EVC devices with tunable operational frequency and vibration amplitude emerged to overcome the problems of resonant devices. So far, a large variety of microstructures, such as Angstrom symbols [30], the "thunderbird" logo [30], trihedrons [30] and $\mathrm{V}$-grooves [31, 32], have been manufactured with the aid of non-resonant EVC devices.

In general, piezo actuator-generated vibrations are applied directly [33] or through flexure hinges [34] to vibration-assisted cutting tools. For example, Heamawatanachai and Bamberg [35] developed a 2-dimensional (2-D) vibration-assisted cutting tool for micromachining, which was driven by a piezoelectric tube. Although this micromachining tool can generate vibration with an amplitude of up to $10 \mu \mathrm{m}$, its operational frequency can only get $300 \mathrm{~Hz}$. Zhu et al. [36, 37] developed a 2-D vibrationassisted cutting tool with a novel Z-shaped flexure hinge that can reach an operational frequency of $500 \mathrm{~Hz}$. Ahn et al. [38] proposed a flexure-based non-resonant 2-D vibration-assisted cutting device, which can be operated at a frequency of $1 \mathrm{kHz}$. Han et al. [39] proposed a flexure-based EVC device for diamond turning. The frequency sweep test revealed that this device could obtain the first natural frequency of up to $1.8 \mathrm{kHz}$. Negishi and Dow [40] developed a non-resonant EVC device for diamond turning with which a high-frequency working mode at $4 \mathrm{kHz}$ could only be achieved with an additional cooling system, indicating the vital importance of the thermal control of the high-frequency non-resonant EVC device. They also developed another kind of non-resonant EVC device without the cooling system; thus, it could only work at up to $400 \mathrm{~Hz}$ [41]. A 2-D non-resonant vibration cutting tool was recently developed by Wang et al. [42] for surface texturing that claimed a working bandwidth of up to $6 \mathrm{kHz}$ based on the results of the frequency sweep test. Nevertheless, it was specially designed for a three-linear-axis machine set-up which is incapable of diamond turning.

Thus, in a word, high-frequency (i.e. over $4 \mathrm{kHz}$ ) nonresonant EVC devices for diamond turning are still rare. This is not only due to the tool and spindle configuration for diamond turning but also the low structural stiffness of the existing vibration-assisted cutting devices, especially in the direction perpendicular to the tool trajectory plane. Highfrequency vibration easily triggers the twisting motion of the diamond tool in this direction, which severely distorts the tool's trajectory. In addition, high-frequency input signals will increase the heat generated by the piezo actuators due to the need for a higher power input. Therefore, overheating of the piezo actuator is another critical problem which must be overcome because it will worsen the machining performance of the non-resonant EVC device, and even cause device failure. Thus, the existing non-resonant EVC devices for diamond turning can only reach relatively low operational frequency, which results in low machining efficiencies and hinders their industrial applications. Moreover, the severe cross-axis coupling between two reciprocating displacements of the diamond tool must be strictly limited, as excessive coupling will distort the tool's elliptical trajectory. Consequently, the dimensional parameters of the non-resonant EVC device must be determined reasonably during the design process to strike a delicate balance between operational frequency, vibration amplitude, coupling effect and heat generation. Thus, the development of a high-frequency non-resonant EVC device for diamond turning with an acceptable coupling ratio and heat generation to meet the urgent need for producing costeffective manufactured microstructured surfaces with great flexibility is a complicated and challenging task and will be the research focus of this paper.

This paper presents the design and experimental tests of a flexure-based non-resonant EVC device for diamond turning microstructured surfaces. A high first natural frequency of up to $5 \mathrm{kHz}$ is achieved, which is higher than most of the existing non-resonant EVC devices for diamond turning without an 
additional cooling system. Section 2 will explain the principle of generating microstructured surfaces by the proposed device. The overall mechanical design and the determination of the key dimensional parameters for the non-resonant EVC device will be described in Section 3. Experimental evaluation of the prototype device will be presented in Section 4. Preliminary machining trials on pure copper to generate the micro-dimple arrays and two-tier microstructures will be presented in Section 5 to demonstrate the effectiveness of this high-frequency nonresonant EVC device for diamond turning.

\section{Principle of generating microstructured surfaces}

Microgroove is a typical structure with application in automobile engine components for reducing friction and improving lubrication [4]. In conventional diamond turning process, when the tool feed per revolution is higher than the width of the manufactured microgrooves, the intact microgrooves without overlap can be generated on the machined surface. To further enlarge the area coverage of the microgroove and strengthen its lubricating performance, a two-tier microstructure with tunable wavelength and height was introduced in this paper, as shown in Fig. 1. This kind of structure includes two tiers: primary microgrooves and secondary sawtooth structures which can be generated by the non-resonant EVC device in one cutting step.

As a two-dimensional machining technique, the tool trajectory generated by the non-resonant EVC device can be split into two displacements in the depth-of-cut (DOC) and cutting directions which can be described as:

$\left[\begin{array}{l}z(t) \\ y(t)\end{array}\right]=\left[\begin{array}{c}\frac{A}{2} \sin (2 \pi f t+\varphi) \\ \frac{B}{2} \sin (2 \pi f t)\end{array}\right]+\left[\begin{array}{c}0 \\ V_{c} t\end{array}\right]$

where $z(t)$ and $y(t)$ are tool displacements in the $z$ - and $y$ directions, respectively. $A$ and $B$ are vibration amplitudes of the diamond tool in corresponding directions. $f$ is the vibration frequency. $\varphi$ is the phase lag between two input sinusoidal signals. $V_{c}$ is the nominal cutting speed.

In the EVC process, the critical upfeed velocity $V_{c r i}$ is described as follow:

$V_{c r i}=2 \pi f A$

The mechanism for the generation of the secondary sawtooth structure under different nominal cutting speed conditions is shown in Fig. 2. When $V_{c}$ is smaller than $V_{c r i}$, the tool trajectory between two contiguous vibration cycle will overlap. The dimension of the peaks for the secondary sawtooth structures in Fig. 2a should satisfy the following equations [43]:
Fig. 1 Two-tier microstructured surfaces generated by the nonresonant EVC device

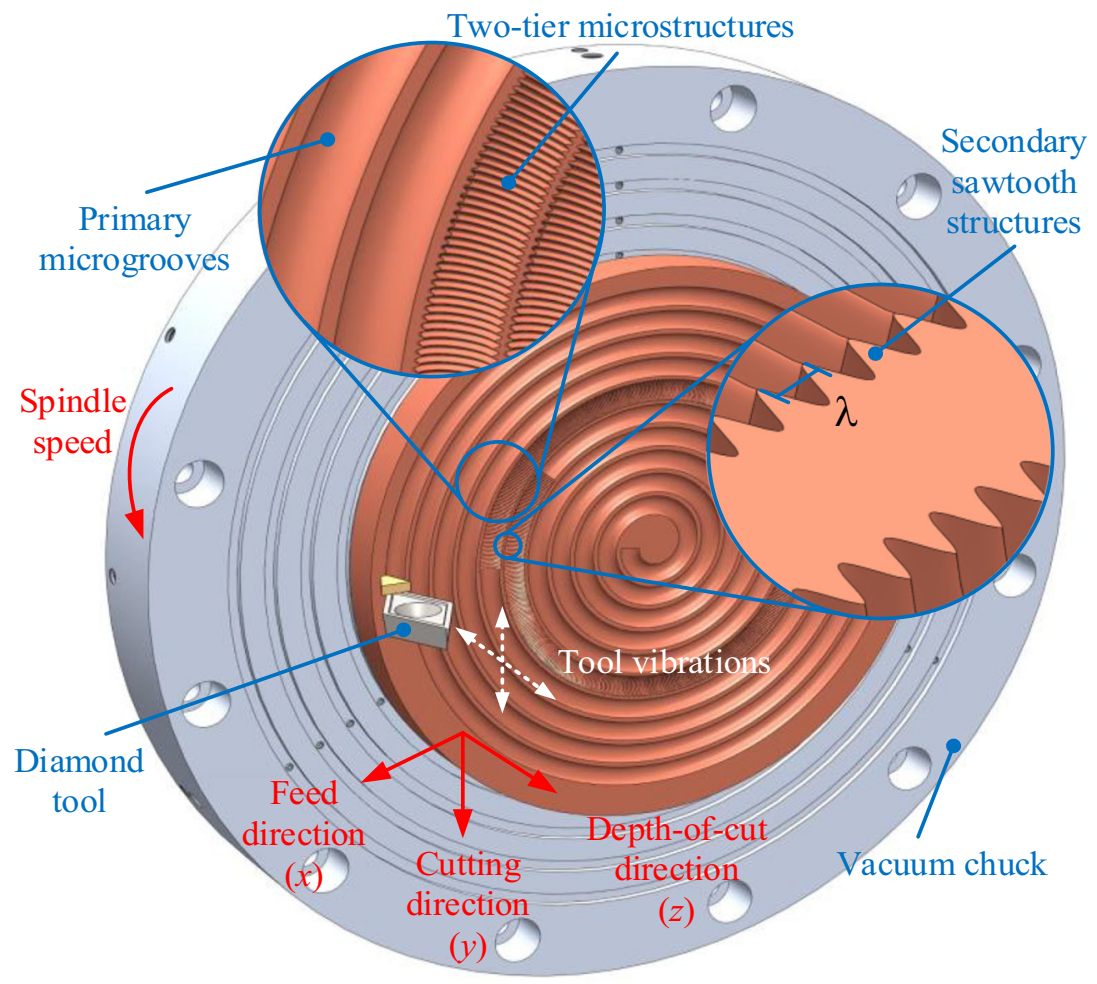


Fig. 2 Generation of sawtooth structures under different nominal cutting speed: (a) $V_{c}<V_{c r i}$, (b) $V_{c}>V_{c r i}$ (a)

$V_{\mathrm{c}}<V_{\text {cri }}$

(b)

$V_{\mathrm{c}}>V_{\mathrm{cri}}$

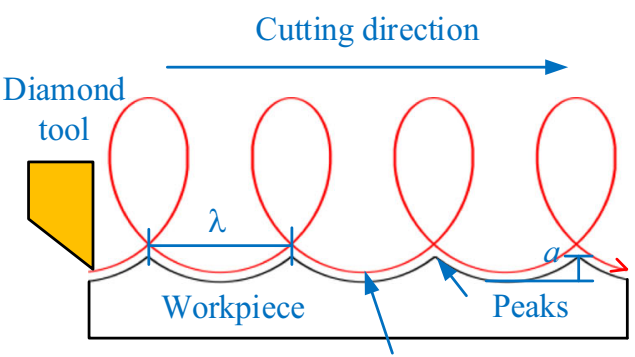

Tool trajectory

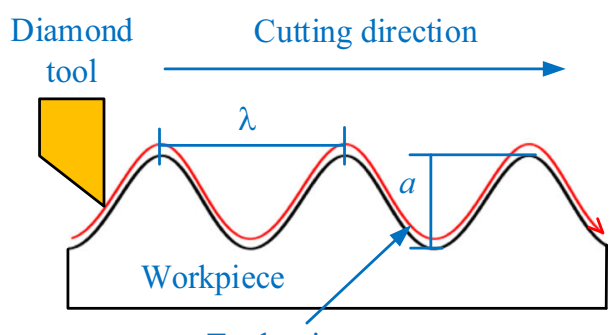

Tool trajectory
$\left\{\begin{array}{c}\frac{B}{2} \cos \left(\frac{\theta_{1}+\theta_{2}}{2}\right) \sin \left(\frac{\theta_{1}-\theta_{2}}{2}\right)+\frac{V_{c}}{2 \pi f}\left(\frac{\theta_{1}-\theta_{2}}{2}\right)=0 \\ \sin \left(\theta_{1}+\varphi\right)=\sin \left(\theta_{2}+\varphi\right)\end{array}\right.$

where $\theta_{1}$ and $\theta_{2}$ are two angular positions corresponding to two adjacent peaks on the machined workpiece. At the same time, the height of the peaks $a$ can be determined by the amplitude of tool vibration in the DOC direction and the angular position $\theta_{1}$ :

$a=\frac{A}{2}\left(1-\left|\sin \left(\theta_{1}+\varphi\right)\right|\right)$

However, when $V_{c}$ is higher than $V_{c r i}$, the tool trajectory will not overlap. Thus, the secondary sawtooth structures, as shown in Fig. 2b, can be obtained. The height $a$ of the periodic sawtooth structures equals to the vibration amplitude $A$ in the DOC direction.

No matter in Fig. 2a or Fig. 2b, the wavelength $\lambda$ is always determined by the frequency of the tool vibration and the nominal cutting speed, which is expressed as follow:

$\lambda=\frac{2 \pi V_{c}}{\omega}=\frac{V_{c}}{f}=\frac{\pi D_{i} N}{f}$

where $N$ is the spindle speed, and $\omega$ is the angular velocity of the tool vibration. $D_{i}$ is the instantaneous cutting diameter.
In brief, for the non-resonant EVC process, adjusting the frequency and amplitude of the tool vibration can change the wavelength and height of the periodic sawtooth structures. Thus, the two-tier microstructured surfaces can be obtained.

\section{Development of the non-resonant EVC device}

\subsection{Mechanical design}

The design goal for the non-resonant EVC device is that it can work at a high frequency of up to $5 \mathrm{kHz}$ with an acceptable level of cross-axis coupling ratio and thermal generation. Figure 3a shows the schematic 3D model of this cutting device, and it mainly includes two parts: a tool holder and a mounting base. Two high-frequency reciprocating displacements are generated by piezo actuators after inputting sinusoidal signals with certain phase lag. Piezo actuators are preloaded by two round end screws which mounted at the bottom. Moreover, low-capacitance piezo actuators were chosen in case of overheating. As mentioned before, the low-stiffness structure of non-resonant EVC device limits its operational frequency. Thus, the combination of the notch hinge prismatic
Fig. 3 3D model of (a) the nonresonant EVC device and its (b) assembly with a diamond turning machine
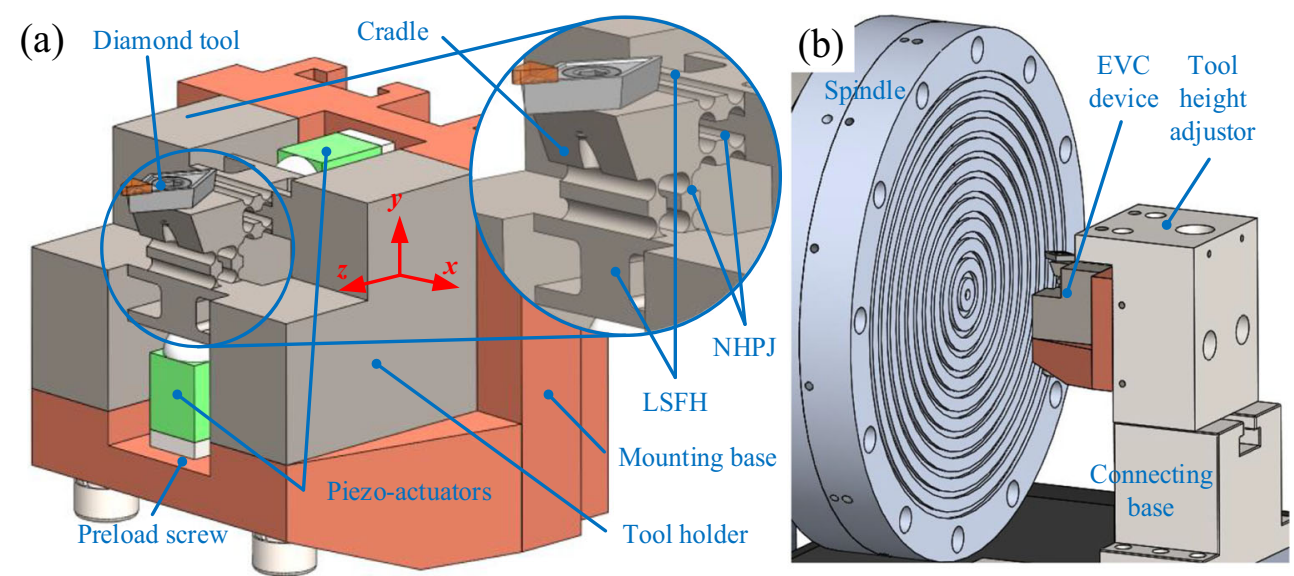
joint (NHPJ) and leaf spring flexure hinge (LSFH) was adopted to improve the structural stiffness and thereby enlarging the device's operational frequency. The NHPJ was designed based on the right circular notch hinges. As a highprecision translational pair, NHPJ guides and transmits two perpendicular motions to the diamond tool. More importantly, it can reduce the cross-axis coupling between the two displacements. Therefore, the diamond tool can move relatively independent in the $z$ - and $y$-directions simultaneously. In Fig. $3 \mathrm{a}$, the tool cradle not only works as a diamond tool holder but also combines two high-frequency reciprocating motions to form an elliptical trajectory. Slide guide on the back of the mounting base can adjust the height of the device easily, so various types of cutting inserts with different tool geometries can be selected and replaced conveniently. The high carbon spring steel $65 \mathrm{Mn}$ was chosen as the material for this non-resonant EVC device, due to its high yield strength required for long service life under cyclic loading. The mechanical properties of $65 \mathrm{Mn}$ are concluded as density $\rho=7850 \mathrm{~kg} / \mathrm{m}^{3}$, Young's modulus $E=210 \mathrm{GPa}$ and Poisson's ratio $\nu=0.288$. As shown in Fig. 3b, this device can be mounted on different diamond turning machines via the tool height adjustor and connecting base. The overall dimension of this device is only $54 \mathrm{~mm} \times 46 \mathrm{~mm} \times 43 \mathrm{~mm}$.

To clarify the design process for the non-resonant EVC device, a flowchart is shown in Fig. 4. The whole process mainly consists of static modelling and determination of key dimensional parameters. After establishing the 3D mechanical structural model of the cutting device, static modelling using the mapped meshing finite element analysis (FEA) and mathematical method were both adopted. The dimensions of the thickness of the LSFH and the neck thickness of the NHPJ were determined considering the effects of modal characteristics and cross-axis coupling, respectively.

\subsection{Mathematical and finite element static modelling}

Although the current non-resonant EVC devices for diamond turning can control the tool trajectory precisely, their operational frequencies are still significantly lower than their resonant counterparts, due to their low structural stiffness. To overcome this shortcoming and mitigate the cross-axis coupling at the same time, static modelling using the mathematical method and mapped meshing finite element method was performed to guide the determination of key dimensional parameters for the designed device.

Radius $R$, neck thickness $t$ and width $b_{1}$ are three critical parameters of NHPJ, playing crucial roles in determining its structural stiffness, as is shown in Fig. 5. With the consideration of the width of the tool insert, the width $b_{1}$ was chosen to be $10 \mathrm{~mm}$ to increase the structural stiffness in the direction that is vertical to the tool trajectory plane. The rotary stiffness $K_{\alpha}$ of the right circular notch hinges of the NHPJ is given by Weisbord and Paros [44]:

$K_{\alpha}=\frac{2 E b_{1}}{9 \pi} \sqrt{\frac{t^{5}}{R}}$

Based on the principle of virtual work, the following equation can be derived:

$\left\{\begin{aligned} W=\frac{1}{2} F_{z} D_{z}+\frac{1}{2} F_{y} D_{y} & =\frac{1}{2} K_{d} D_{z}{ }^{2}+\frac{1}{2} K_{d} D_{y}{ }^{2}+\Delta U_{z}+\Delta U_{y} \\ \Delta U_{i} & =4 \Delta U_{f}(i=z, y)\end{aligned}\right.$

where $W$ is the virtual work done by $F_{z}$ and $F_{y} . \Delta U_{i}$ is the total rotational energy, and $\Delta U_{f}$ is the rotational energy of each notch hinge. $K_{d}$ is the stiffness of the LSFH [45]:

$K_{d}=\frac{4 E b_{2} l^{3}}{L_{1}{ }^{3}}$

where $b_{2}, l$ and $L_{1}$ are the width, thickness and length of the LSFH, respectively.

The expression of $\Delta U_{f}$ is shown in the following equation:
Fig. 4 The flowchart of the design process for the nonresonant EVC device

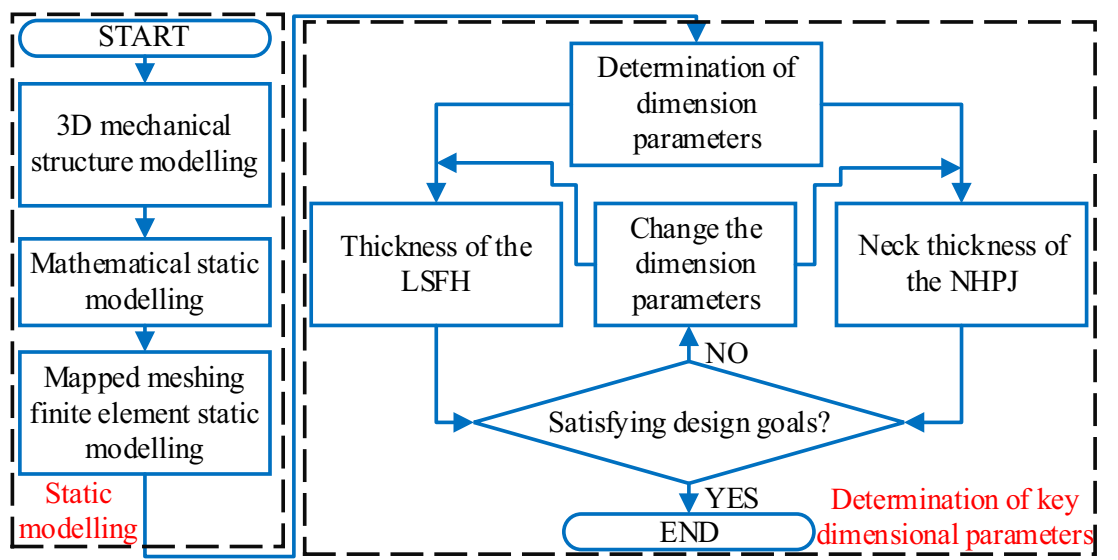


Fig. 5 Schematic and moving mechanism of the combination of the LSFH and NHPJ

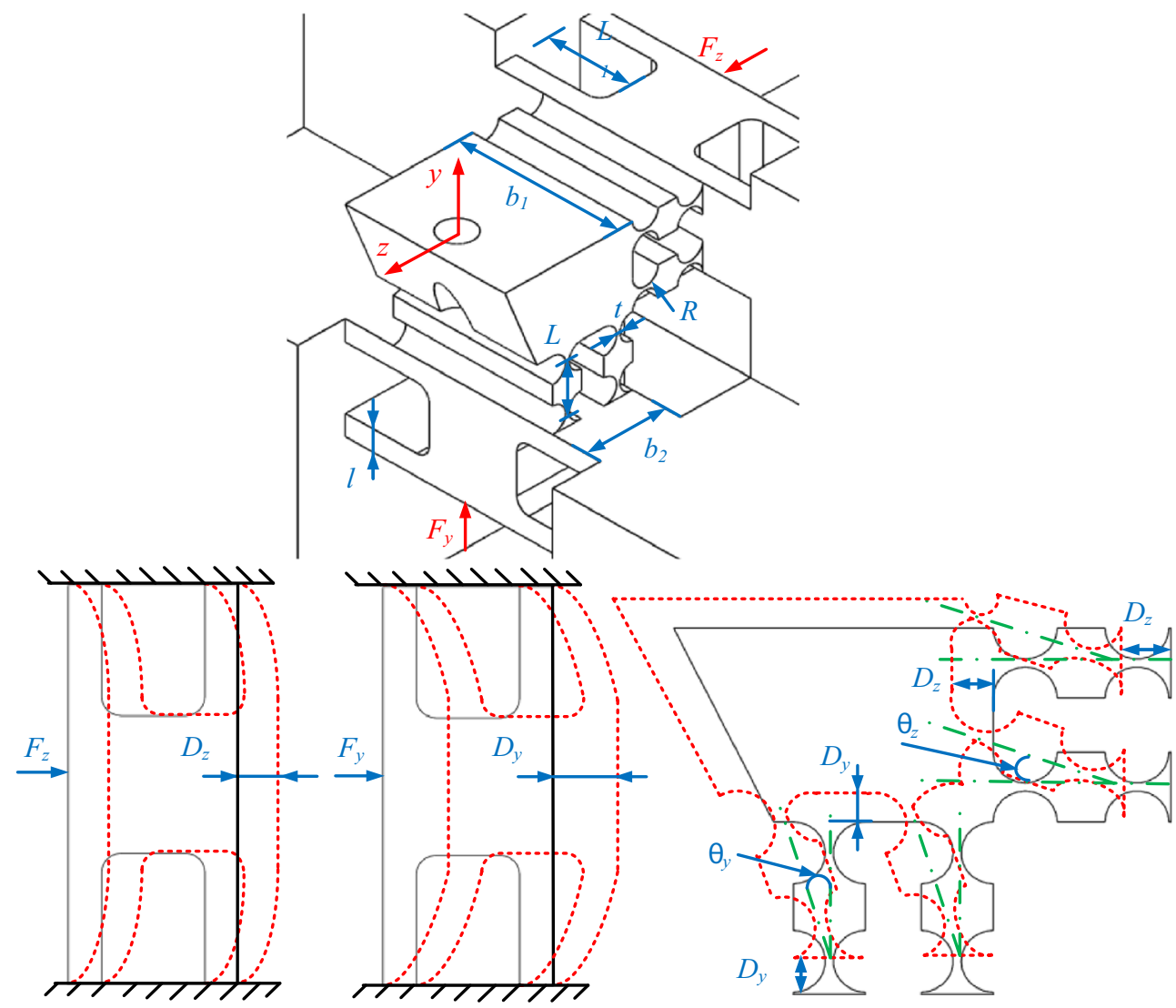

where $L$ is the distance between two notch hinges.

The LSFH and NHPJ have the same dimensions in both $z-$ and $y$-directions, and the external forces $F_{z}$ and $F_{y}$ are equal. Thus, the equivalent stiffness of the combination of LSFH and NHPJ in both $z$ - and $y$-directions can be derived based on Eqs. (8) and (9):

$K_{e q l}=K_{d}+\frac{4 K_{\alpha}}{L^{2}}$

Eq. (10) can be used to estimate the equivalent stiffness of the combination of the LSFH and NHPJ.

In addition to the mathematical method, static finite element modelling using ANSYS 18.0 was performed as well. The bottom surface of the mounting base was set to be fixed support, as shown in Fig. 6. The cutting and thrust forces in the vibration-assisted diamond turning are usually in the order of $10^{-1} \mathrm{~N}[46,47]$, which are far less than actuation force, so they are ignored.

Currently, coarse tetrahedral meshes generated by the automatic meshing method are widely used in previous work for modelling the non-resonant EVC device [39, 48]. However, as shown in Fig. 6, more regular hexahedron meshes can be generated with the aid of the mapped meshing method, which can increase the modelling accuracy [49-51]. Thus, in the following section, the mapped meshing FEA was employed to predict the coupling ratio and modal characteristics of this non-resonant EVC device to help determine its key dimensional parameters of the NHPJ and LSFH.

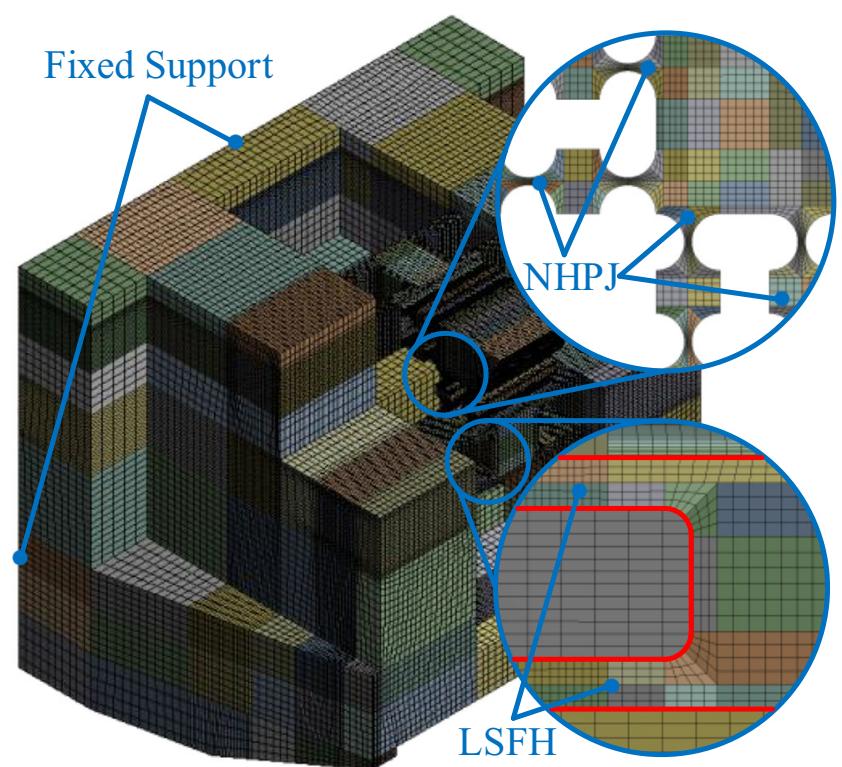

Fig. 6 The mapped meshing finite element model for the non-resonant EVC device 


\subsection{Determination of key dimensional parameters}

\subsubsection{Thickness of the LSFH}

The thickness $l$ of the LSFH is a critical dimensional parameter which has a significant impact on the equivalent stiffness and thereby determining the modal characteristics of the nonresonant EVC device, such as the sequence and vibrational mode shapes of its natural frequencies. In the process of determining the dimension of the thickness of the LSFH, the finite element modal analysis was used to identify the natural frequency of the designed device. The vibrational mode shapes of the first three natural frequencies are shown in Fig. 7. In mode shape I, the tool cradle moves in a straight line along the $y$-direction denoting the reciprocating motion of the diamond tool in the cutting direction. On the contrary, in mode shape II, it moves along the $z$-direction representing the movement in the DOC direction. Mode shape III is the undesired mode shape which manifests the twisting of the tool holder. It is worthwhile to point out that the sequence of the mode shapes might be different under different thickness of the LSFH.

The first two mode shapes of this device should be coincident with the diamond tool's displacements in the cutting and DOC directions. The frequencies of the first two orders determine the upper limit of its operational frequency. Thus, the value of the thickness $l$ should be chosen to adjust the mode shape I and mode shape II to be the first two mode shapes of the designed device and increase its natural frequency as high as possible. Under different thickness, the modal analysis identified the sequence of the first three resonant frequencies of the proposed device. The results are shown in Table 1.

When the thickness is $1.6 \mathrm{~mm}$, the mode shape III is the first mode shape. With the continuous decrease of the thickness of the LSFH, the mode shapes I and II start to become the first and the second mode shape, gradually overpassing the mode shape III. Nevertheless, the resonant frequency
Table 1 Simulation results of finite element modal analysis

\begin{tabular}{ll}
\hline Thickness $l(\mathrm{~mm})$ & $\begin{array}{l}\text { Sequence and frequencies }(\mathrm{Hz}) \text { of the } \\
\text { first three mode shapes }\end{array}$ \\
\hline 1.6 & III: 16000 ; I: 16608 ; II: 18277 \\
1.5 & III: 15947 ; I: 16103 ; II: 17382 \\
1.4 & I: 15462 ; III: 15861 ; II: 16412 \\
1.3 & I: 14700 ; II: 15421 ;II: 15796 \\
1.2 & I: 13846 ; II: 14379 ; III: 15715 \\
\hline
\end{tabular}

continuously decreases as well, because a smaller thickness would reduce the equivalent stiffness of the LSFH, especially in the direction that is perpendicular to the tool vibration plane. The thickness of the LSFH was confirmed to be $1.3 \mathrm{~mm}$ to achieve a higher operational frequency.

\subsubsection{Neck thickness of the NHPJ}

As mentioned previously, the cross-axis coupling of two cyclic displacements generated from piezo actuators could have a negative effect on the transmission of the non-resonant EVC device and its machining accuracy. Although the neck thickness of the NHPJ has less impact on modal characteristics, it has a vital influence on the cross-axis coupling. In this paper, the degree of the cross-axis coupling is described using the coupling ratio $C$. The cross-axis coupling ratios $C_{1}$ and $C_{2}$ are defined in the following equations:

$$
C_{1}=\frac{\Delta y}{D_{z}} \text { and } C_{2}=\frac{\Delta z}{D_{y}}
$$

where $\Delta z$ and $\Delta y$ are maximum parasitic displacements when the piezo actuator along the $y$ - or $z$-direction is actuated only. $D_{z}$ and $D_{y}$ are maximum output displacements in the $z$ - and $y$ directions when only one piezo actuator is actuated in the corresponding direction.

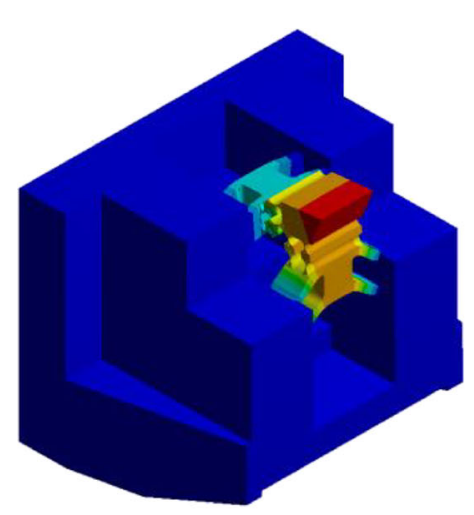

(a) Mode Shape I

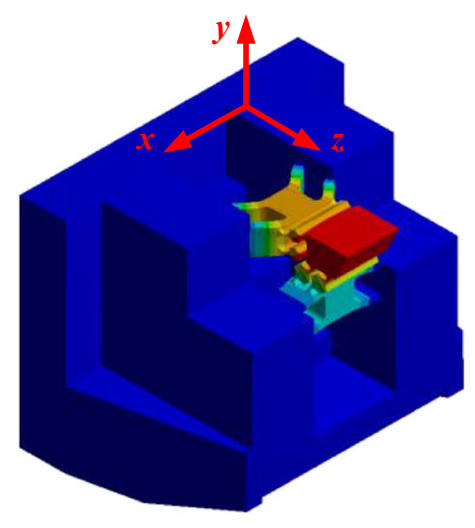

(b) Mode Shape II

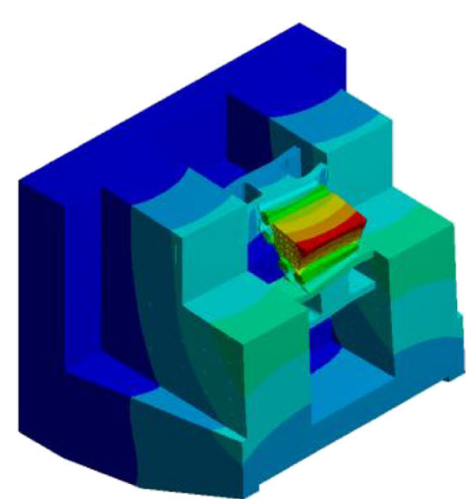

(c) Mode Shape III

Fig. 7 The first three vibrational mode shapes of the designed device: (a) mode shape I; (b) mode shape II; (c) mode shape III 


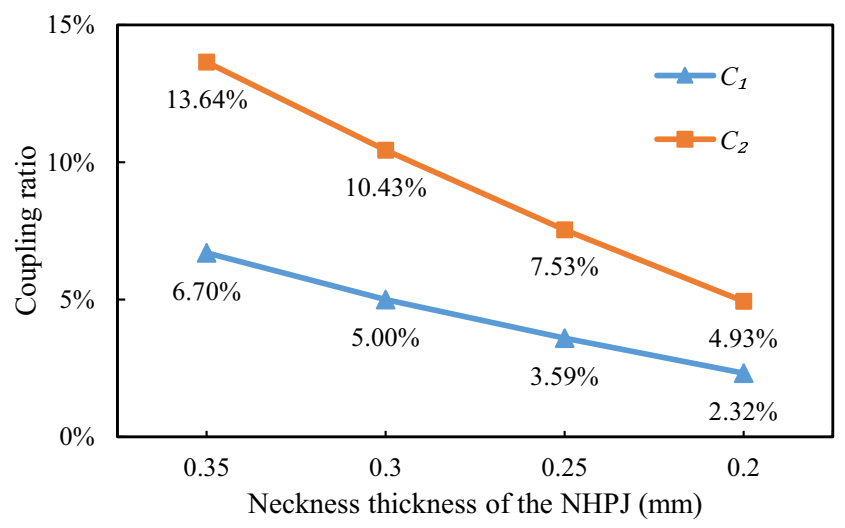

Fig. 8 Cross-axis coupling ratio under different neck thickness

In this paper, the mapped meshing FEA was carried out to determine the neck thickness of the NHPJ, which aims to keep the coupling ratio to an acceptable level. In this analysis, the radius of the NHPJ is set to be $0.8 \mathrm{~mm}$, considering the attainable machining accuracy for the fabrication of the designed device. The value of neck thickness varies from 0.2 to $0.35 \mathrm{~mm}$, according to the dimensional range in previous researches [39, 42, 48]. The results of the calculated cross-axis coupling ratio by the FEA are shown in Fig. 8.

As the neck thickness of the NHPJ continuously decreases, the coupling ratio slumps. The coupling ratio in the cutting direction is two times higher than that in the DOC direction. This can be attributed to the beak-shaped tool cradle, which will deteriorate the degree of coupling in the cutting direction. Even so, when the neck thickness is $0.2 \mathrm{~mm}$, the coupling ratio in the cutting direction decreases to be $4.93 \%$. Hence, considering the manufacturing feasibility, the dimension of the neck thickness $t$ is confirmed to be $0.2 \mathrm{~mm}$. Several important dimensional parameters of the non-resonant EVC device proposed in this paper are given in Table 2 .

The equivalent stiffness of the combination of the LSFH and NHPJ for the designed device in the $z$ - and $y$-directions is $52.1 \mathrm{~N} / \mu \mathrm{m}$ and $50.9 \mathrm{~N} / \mu \mathrm{m}$, based on the results of the mapped meshing FEA. The small difference can be attributed to the fact that the tool cradle is not exactly symmetrical. From Eq. (10), the equivalent stiffness of the combination of the LSFH and NHPJ was calculated as $56.1 \mathrm{~N} / \mu \mathrm{m}$. The relative stiffness

Table 2 Dimensional parameters of the designed non-resonant EVC device

\begin{tabular}{ll}
\hline Parameters & Values (mm) \\
\hline Radius $R$ (NHPJ) & 0.8 \\
Neck thickness $t$ (NHPJ) & 0.2 \\
Width $b_{1}$ (NHPJ) & 10 \\
Length $L$ (NHPJ) & 4.4 \\
Width $b_{2}$ (LSFH) & 5 \\
Thickness $l$ (LSFH) & 1.3 \\
Length $L_{1}$ (LSFH) & 5.5 \\
\hline
\end{tabular}

differences along the $z$ - and $y$-directions are $7.13 \%$ and $9.27 \%$, indicating good consistency between the mapped meshing finite element model and the established mathematical model.

\section{Experimental results and discussions}

\subsection{Experimental setup}

A prototype of the designed non-resonant EVC device was manufactured and assembled. The performance of this device was evaluated through thermal, dynamic and tool trajectory tests, which would be discussed in the following sections. As shown in Fig. 9, two excitation signals were generated by a dual-channel function generator (TGF4042, Aim-TTi) and then applied to piezo actuators (PSt150, Piezomechanik). In this process, the low-voltage signals need to be amplified by the power amplifier (E01.A2, CoreMorrow) before driving the piezo actuators. The displacements of the diamond tool in the cutting and DOC directions were captured by two capacitive sensors (Lion Precision CPL190) whose bandwidth is $15 \mathrm{kHz}$. The measurement results were collected and recorded by a data acquisition card (USB-1608HS, Measurement Computing), and its sampling frequency is $65 \mathrm{kHz}$.

\subsection{Analysis of heat generation}

Heat and temperature management is a crucial problem and has to be concerned in the first place, as overheating interferes with the performance and reliability of the piezo actuator. A long-term operation under high temperature can even damage the piezo actuators. The heat generation power $P_{h}$ of each piezo actuator is expressed as:

$P_{h}=\frac{1}{2} K U^{2} C f$

where $U$ and $f$ are the peak-to-peak voltage and the frequency of input harmonic signal, respectively. $C$ is the capacitance of the piezo actuator, which is $1.8 \mu \mathrm{F}$. $K$ is the proportion of the average power consumption that is converted into heat. Negishi $[52,53]$ reported that, based on the experimental results, $22 \%$ of the electrical power flowing through the actuator was lost to heat. Thus, considering the extreme condition, $K$ is chosen to be 0.25 in this paper.

Due to the upper limit of the power amplifier's drive capability, there is a strong negative correlation between the highest operational frequency and the input voltage. Thus, several tests were carried out to investigate the relationships between the highest operational frequency, the heat generation power and the input voltage. The results are illustrated in Fig. 10. 
Fig. 9 Experimental setup

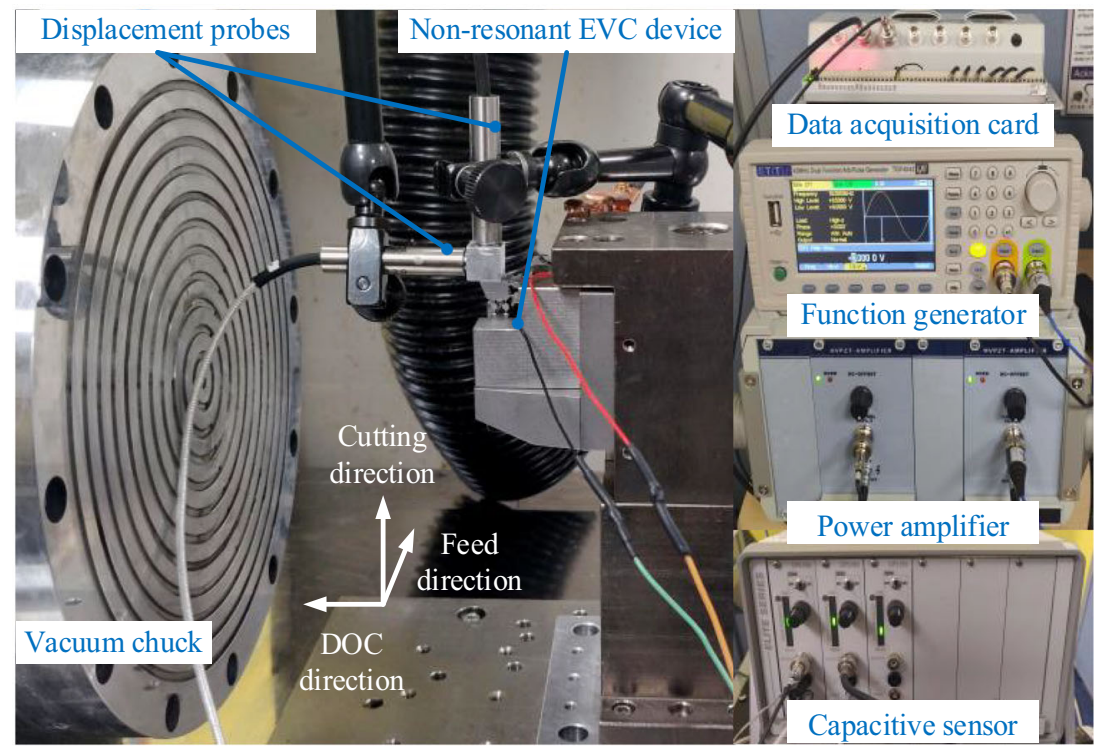

The voltage of the input signals varies from 12 to $132 \mathrm{~V}$ instead of $150 \mathrm{~V}$ to protect the piezo stacks from damage. With the increase of input voltage, the heat generation power of the piezo actuator increases, and reaches its maximum value when the voltage is $132 \mathrm{~V}$. At this moment, the heat generation power is only $2.74 \mathrm{~W}$, which is competent under an air-cooled working condition.

\subsection{Experimental modal test}

In order to investigate the dynamic response and determine the operational frequency range of the proposed device, a series of experimental modal tests were carried out using an impact hammer (PCB Piezotronics 086C03) and accelerometers (PCB Piezotronics 333B50). The testing results are illustrated in Fig. 11.

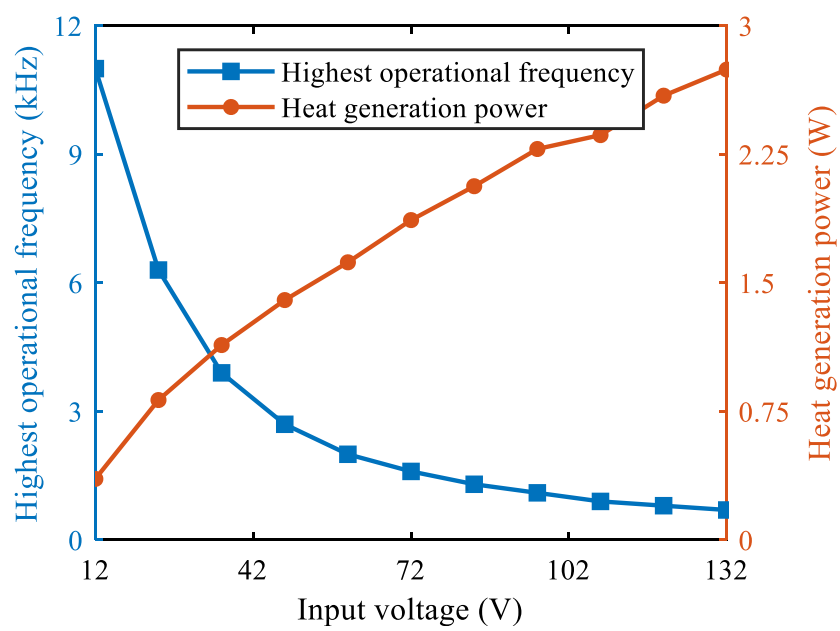

Fig. 10 The highest operational frequency and heat generation power of the non-resonant EVC device under different input voltages
As shown in Fig. 11a, the frequency response of the designed device in the DOC and cutting directions are in good agreement in the frequency ranges of below $5 \mathrm{kHz}$ and above $6 \mathrm{kHz}$, except two close response peaks at 5.1 and $5.5 \mathrm{kHz}$. This phenomenon indicates that the first natural frequency of the developed device in the cutting direction is most likely between 5.1 and $5.5 \mathrm{kHz}$.

To verify this assumption, the frequency sweep tests were carried out by setting the input voltage for the piezo actuator in the cutting direction at $12 \mathrm{~V}$. The frequency swept from 0 to $10 \mathrm{kHz}$ with an interval of $100 \mathrm{~Hz}$. The amplitude-frequency response is illustrated in Fig. 11b. The results of the frequency sweep tests are in good agreement with those of the impact hammer modal test. It can, therefore, identify that the first natural frequency of the designed device is $5.2 \mathrm{kHz}$ in the cutting direction, whereas its first natural frequency in the DOC direction is $8.5 \mathrm{kHz}$. It is worth mentioning that the natural frequency obtained from the FEA is higher than those from experiments. In addition to the manufacturing errors of the proposed device, imperfect and complicated contacts between piezo actuators, tool holder and mounting bases are other reasons for the difference. Nevertheless, the upper limit of the operational frequency for the designed non-resonant EVC device was confirmed to be $5 \mathrm{kHz}$ which is slightly lower than its first natural frequency.

\subsection{Evaluation of the coupling effect}

The coupling tests were performed by using two sinusoidal input signals of $500 \mathrm{~Hz}$ for both piezo actuators. The two inputs have the same voltage of $132 \mathrm{~V}$. Please note that only one piezo actuator was activated in each test, while the piezo actuator along the other direction has no input signal. The displacements of the proposed non-resonant EVC device in 
Fig. 11 (a) Experimental modal tests. (b) Frequency response of the non-resonant EVC device with swept excitation in the cutting direction

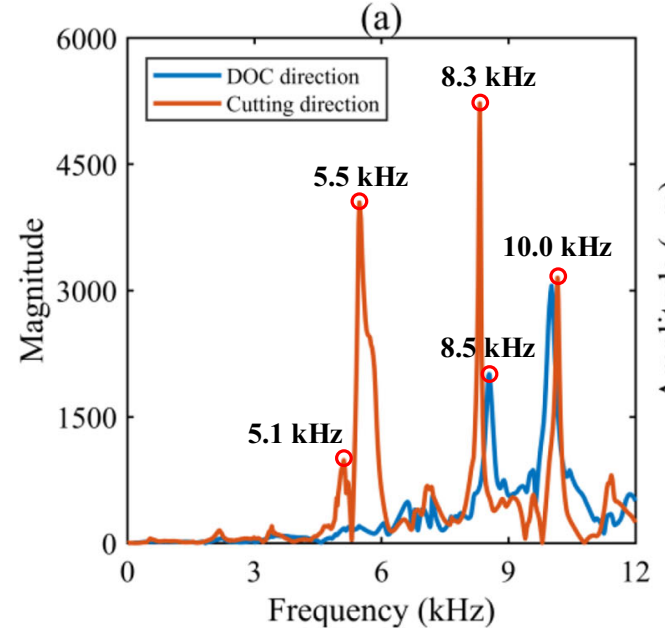

the cutting and DOC directions were captured, which are shown in Fig. 12.

As shown in Fig. 12a, when the piezo actuator along the DOC direction was actuated only, the maximum parasitic displacement in the cutting direction is $0.08 \mu \mathrm{m}$, whereas the maximum displacement in the DOC direction is $1.70 \mu \mathrm{m}$. Likewise, the results in Fig. 12b illustrates that, when the piezo actuator along the cutting direction was solely actuated, the maximum parasitic displacement in the DOC direction is $0.20 \mu \mathrm{m}$. At this moment, the maximum displacement in the cutting direction is $2.05 \mu \mathrm{m}$. Thus, the calculated cross-axis coupling ratios $C_{1}$ and $C_{2}$ are $4.71 \%$ and $9.76 \%$, respectively. The actual cross-axis coupling ratio is as twice as the results obtained from FEA, whereas it is very close to the simulation results when the neck thickness is $0.3 \mathrm{~mm}$. The manufacturing error of the developed device would be a major source that contributed to such a big difference. Despite that, the cross-axis coupling ratio is still at an acceptable level.

\subsection{Tests on the elliptical trajectory}

Two sinusoidal input excitation signals with different phase lags were applied to the piezo actuators whose voltage varies from 24 to $132 \mathrm{~V}$. Based on the results from the experimental modal tests, the trajectory tests were carried out from 500 to $5 \mathrm{kHz}$. Notably, as a result of the limitation of the power amplifier's drive capability, the voltage of the input signal needs to be tuned according to its input frequency. The displacements of the designed device in the cutting and DOC directions under different input signals were collected and combined. Then, the device's elliptical trajectories were obtained and were shown in Fig. 13.

With the decrease of the input voltage, the amplitude of the elliptical trajectory reduced from $2.1 \mu \mathrm{m}$ to several hundred nanometres, showing a good manufacturing range of this nonresonant $\mathrm{EVC}$ device. When the phase lag between two input signals varied from 0 to $180^{\circ}$, the tool's trajectory was firstly compressed to a straight line and then stretched into a regular
Fig. 12 Experimental results of the cross-axis coupling: (a) the DOC direction, (b) the cutting direction (a)

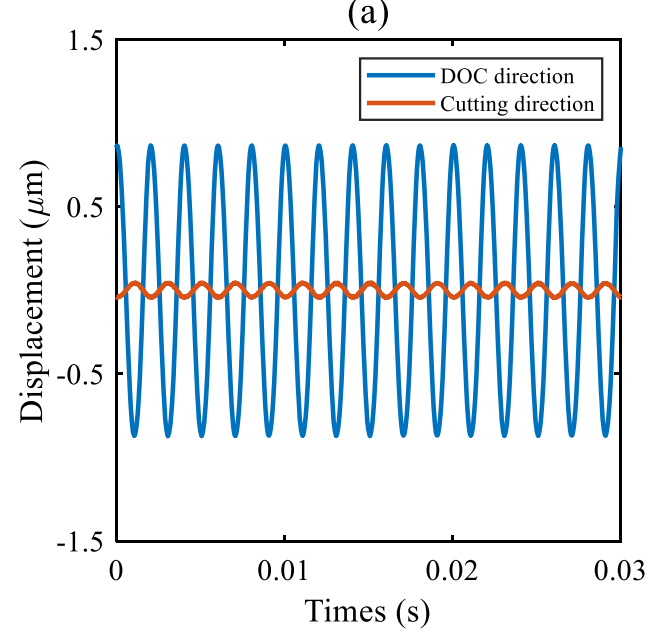

(b)

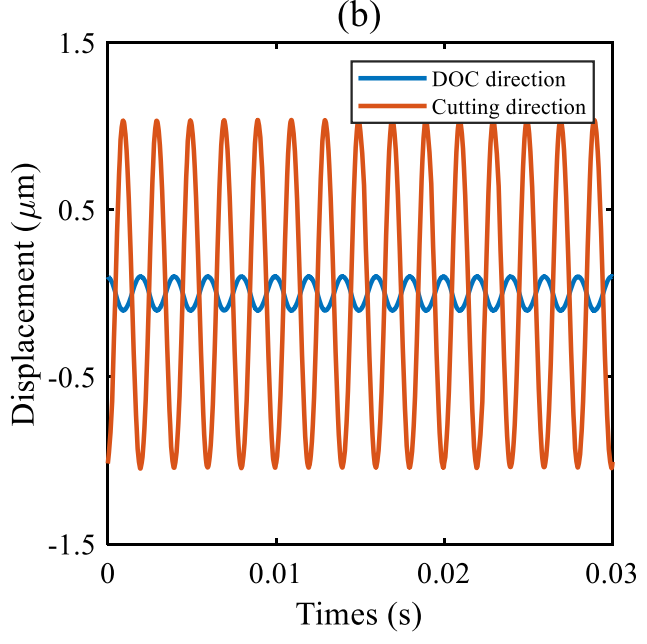




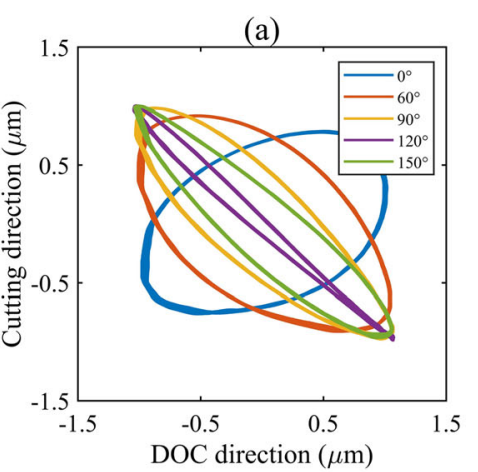

(d)

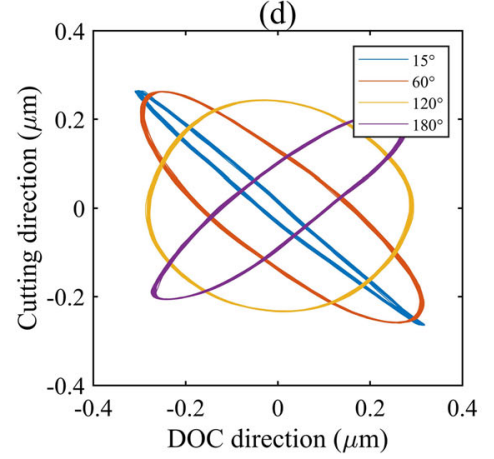

(b)

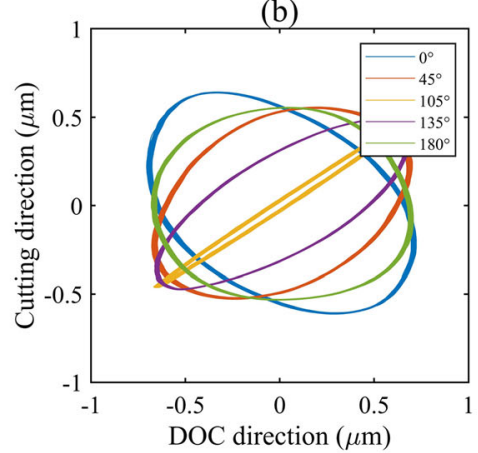

(e)

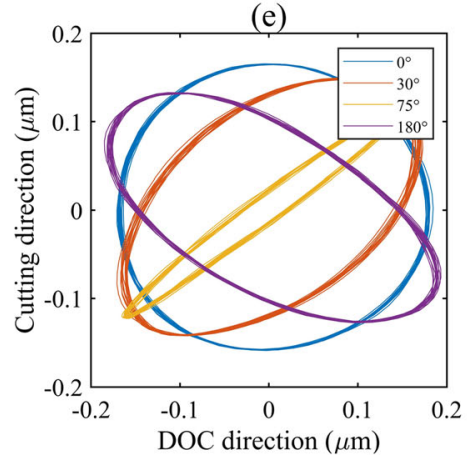

(c)

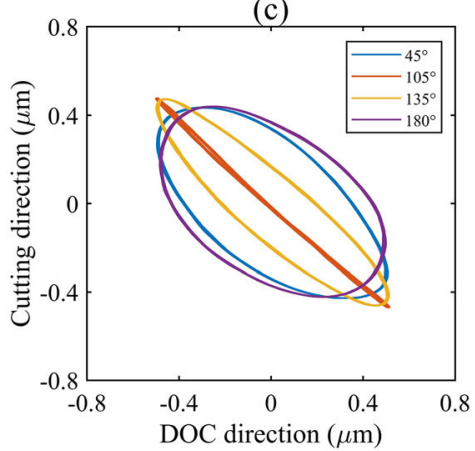

(f)

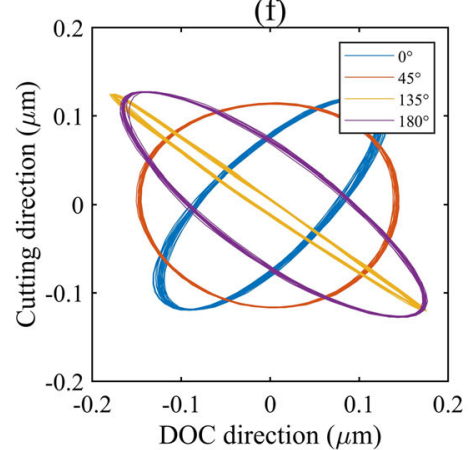

Fig. 13 Elliptical trajectories of the designed device under different operational conditions: (a) $500 \mathrm{~Hz}$ at $132 \mathrm{~V}$, (b) $1 \mathrm{kHz}$ at $96 \mathrm{~V}$, (c) $1.5 \mathrm{kHz}$ at $72 \mathrm{~V}$, (d) $2.5 \mathrm{kHz}$ at $48 \mathrm{~V}$, (e) $4 \mathrm{kHz}$ at $30 \mathrm{~V}$, (f) $5 \mathrm{kHz}$ at $24 \mathrm{~V}$

ellipse. The similar trend appeared in all operational frequencies. Thus, the experimental results approve that regular elliptical trajectory of the designed device can always be generated under a high frequency of up to $5 \mathrm{kHz}$.

\section{On-machine performance tests}

\subsection{Preliminary machining performance tests}

The effectiveness of the proposed non-resonant EVC device was evaluated through preliminary diamond turning tests. Two machining trials were conducted on a disc-shaped pure copper workpiece under different operational conditions. Two concentric annuli on the workpiece represent these two machining areas. The tool feed per revolution, DOC and spindle speed were set to be $5 \mathrm{~mm} / \mathrm{min}, 3 \mu \mathrm{m}$ and $30 \mathrm{rev} / \mathrm{min}$, respectively. The nose radius of the diamond tool is $0.5 \mathrm{~mm}$. Different operational conditions of the device were employed, and the detailed parameters are listed in Table 3. Two small square areas on the machined surface were selected for measurement by a white light interferometer (Zygo CP300). The distances between the centres of the measurement areas and the workpiece's centre of rotation are $11.1 \mathrm{~mm}$ and $7.6 \mathrm{~mm}$, respectively. These two distances were used to estimate the designed values of the wavelength of the machined microstructures in measurement areas.
Figure 14a shows the machined micro-dimple arrays generated under the operational frequency of $500 \mathrm{~Hz}$ (Exp. 1). When the operational frequency is $1000 \mathrm{~Hz}$ (Exp. 2), the nominal cutting speed $V_{c}$ is higher than its corresponding critical upfeed velocity $V_{c r}$, so the secondary sawtooth structures were obtained. The generated two-tier microstructures are shown in Fig. 14b.

The comparison on the wavelengths and heights between the designed and machined microstructures along measurement lines is shown in Table 4. The measured wavelengths of the machined microstructures agree well with the designed values in both machining trials with errors of $-0.86 \%$ and $-1.26 \%$, owing to the excellent frequency stability of the designed device. The measured heights of the machined microstructures are $2.27 \mu \mathrm{m}$ and $1.34 \mu \mathrm{m}$ with errors of $0.17 \mu \mathrm{m}$ and $-0.16 \mu \mathrm{m}$. The difference is less than $10.67 \%$. The roughness of the machined surfaces is measured after application of a high-pass filter with a cut-off frequency of $177 \mathrm{~Hz}$ to eliminate waviness and form components. The surface roughness $R \mathrm{a}$ is $46 \mathrm{~nm}$ and $66 \mathrm{~nm}$ in Exp. 1 and Exp. 2, respectively.

Table 3 Operational conditions in the machining trials

Experiment no. Operational frequency $(\mathrm{Hz}) ; \quad$ Cutting diameter $(\mathrm{mm})$ input voltage (V)

\begin{tabular}{lll}
\hline 1 & $500 ; 132$ & $20-26$ \\
2 & $1000 ; 96$ & $13-19$ \\
\hline
\end{tabular}



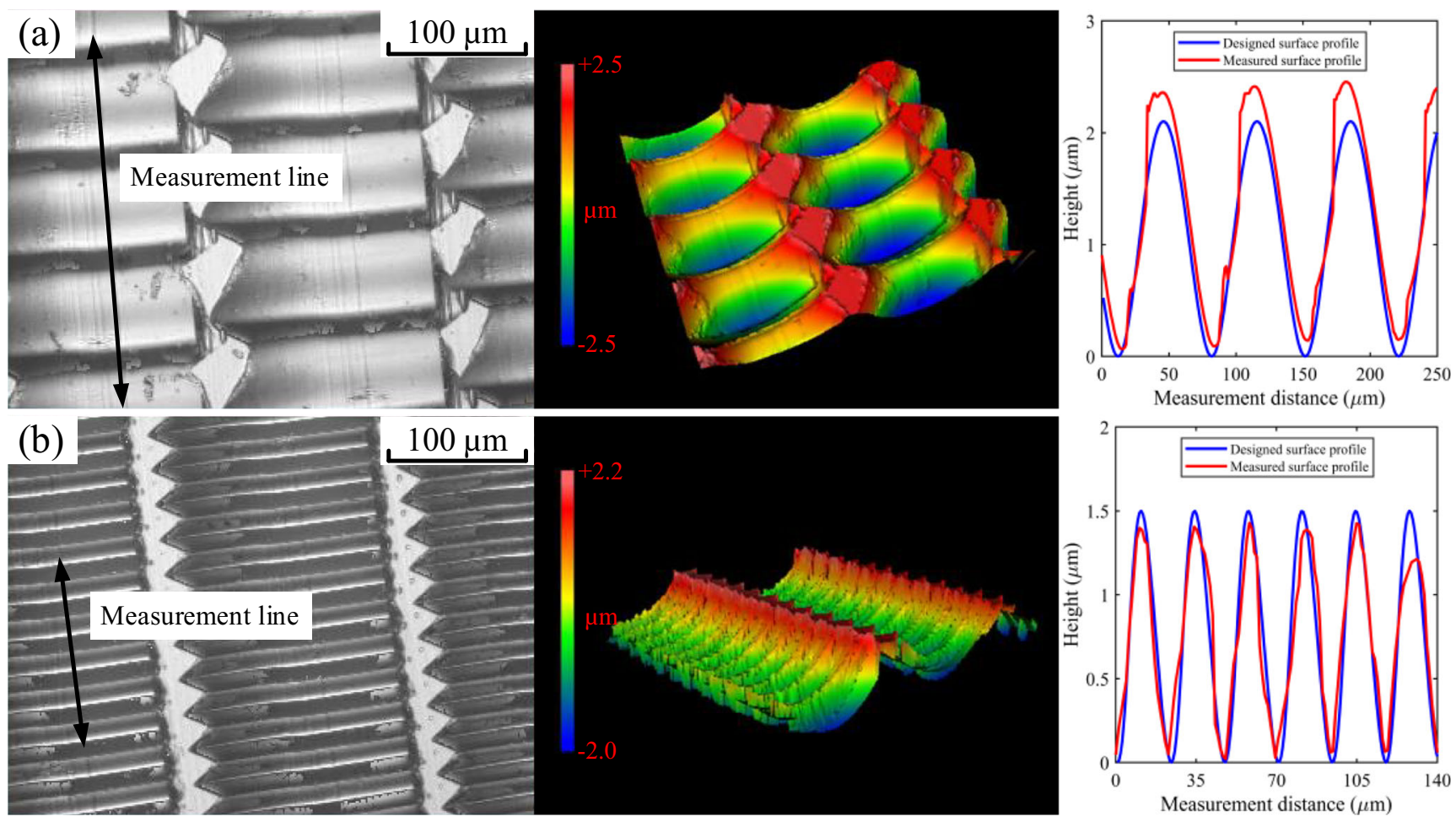

Fig. 14 Microphotographs, 3D surface topographies and sectional profiles of the machined structures: (a) Exp. 1, (b) Exp. 2

Table 4 Dimensional errors of the machined microstructures

\begin{tabular}{llllr}
\hline Experiment no. & Dimensions & Designed values $(\mu \mathrm{m})$ & Measured values $(\mu \mathrm{m})$ & Errors $(\%)$ \\
\hline 1 & Wavelength & 69.7 & 69.1 & $-0.86 \%$ \\
& Height & 2.1 & 2.27 & $8.10 \%$ \\
2 & Wavelength & 23.9 & 23.6 & $-1.26 \%$ \\
& Height & 1.5 & 1.34 & $-10.67 \%$ \\
\hline
\end{tabular}

\subsection{Benchmarking with other work}

The comparison of the key performance indicators of the proposed device with other published work is shown in Table 5.

In summary, the prototype of the designed non-resonant EVC device can work at a high operational frequency of up to $5 \mathrm{kHz}$. The equivalent stiffness at the tool tip reaches $50.9 \mathrm{~N} / \mu \mathrm{m}$ in the cutting direction and $52.1 \mathrm{~N} / \mu \mathrm{m}$ in the DOC direction. Compared with the existing work, the highstiffness property of the designed device increases its operational frequency but sacrifices the amplitude outputs in both directions to some extent. Thus, the vibration amplitudes can

Table 5 Comparison of the key performance indicators with other published work

\begin{tabular}{|c|c|c|c|c|}
\hline Features & This work & Li et al. [31] & Han et al. [39] & Wang et al. [42] \\
\hline Operational frequency $(\mathrm{kHz})$ & 5 & 2.5 & 1.8 & 6 \\
\hline Vibration amplitude $(\mu \mathrm{m})$ & 2 & 2.5 & 24 & 16 \\
\hline Equivalent stiffness $(\mathrm{N} / \mu \mathrm{m})$ & $50.9 ; 52.1$ & $\mathrm{~N} / \mathrm{A}$ & 25 & $0.4 ; 1.5$ \\
\hline Machinable shapes & Circular & Circular & Circular & Circular; trapezoidal dimples \\
\hline Surface roughness $R \mathrm{a}(\mathrm{nm})$ & $<66$ & $<59$ & N/A & N/A \\
\hline Machined materials & Pure copper & $\mathrm{N} / \mathrm{A}$ & $6061 \mathrm{Al}$ & Aluminium alloy \\
\hline If applicable to diamond turning & Yes & Yes & Yes & No \\
\hline
\end{tabular}


reach over $2 \mu \mathrm{m}$, which is relatively lower than some existing designs. The designed non-resonant EVC device can generate circular microstructures such as micro-dimple arrays and twotier microstructures with tunable wavelength and height. Although trapezoidal microstructures have been generated by some designs, they are not applicable to diamond turning. The surface roughness of the complex microstructures generated in this work is less than $66 \mathrm{~nm}$, which is slightly higher than those machined by Li et al. [31]. However, merely simple $\mathrm{V}$-grooves were generated in their work. The surface roughness is not available in other references. The preliminary diamond turning trials are currently carried out on pure copper, and its performance on hard-to-machine materials, such as stainless steel, silicon, silicon carbide and optical glasses, deserves further investigation. Nevertheless, the good agreement in the designed and the measured dimensions of the microstructures verified the effectiveness of this high-frequency non-resonant EVC device for diamond turning.

\section{Conclusions}

A flexure-based high-frequency non-resonant EVC device with tunable operational frequency and amplitude for diamond turning microstructures was developed and evaluated in this study. The flexure-based design that combines the LSFH and NHPJ can not only transmit and connect the reciprocating displacements of the diamond tool but also offers an improved operational frequency. The conclusions can be drawn as follows:

(1) A decrease in the neck thickness of the NHPJ could reduce the cross-axis coupling ratio, while a reduction in the thickness of the LSFH could not only reduce the natural frequency of the designed non-resonant EVC device but also change the sequence of its vibrational mode shapes.

(2) The systematic experimental evaluation of the proposed device demonstrated that it could achieve a highfrequency and non-resonant working mode with an acceptable level of cross-axis coupling ratio and thermal generation. Moreover, the device's elliptical trajectories with different amplitudes could be conveniently generated by tuning the operational frequency, input voltage and phase lag.

(3) The prototype of the designed non-resonant EVC device can work at an operational frequency of up to $5 \mathrm{kHz}$, which is higher than its non-resonant counterparts in the field of diamond turning. Its vibration amplitudes in the cutting and DOC directions can reach over $2 \mu \mathrm{m}$, although the high-frequency and high-amplitude working modes cannot be achieved simultaneously due to the limitation of the drive capability of the current power amplifier.

(4) The designed non-resonant EVC device can accurately generate complex microstructures such as micro-dimple arrays and two-tier microstructures with tunable wavelength and height on pure copper. Furthermore, the wavelength and height errors of less than $1.26 \%$ and $10.67 \%$ were demonstrated in the machining trials, showing good consistency with the designed dimensions of the bespoke microstructures.

Authors' contributions Zhengjian Wang and Xichun Luo contributed to the conceptualization, writing and editing. Zhengjian Wang, Fei Ding, Liang Yang and Jianguo Zhang contributed to the methodology. Haitao Liu and Andrew Cox provided resources. Wenlong Chang performed project administration.

Funding This work was supported by the EPSRC (EP/K018345/1, EP/ T024844/1), Royal society-NSFC International exchange scheme (IEC/ NSFC/181474). The authors would also gratefully acknowledge the financial support from the China Scholarship Council (CSC).

Availability of data and materials All data underpinning this publication are openly available from the University of Strathclyde Knowledge Base.

\section{Compliance with ethical standards}

Conflict of interest The authors declare that they have no conflicts of interest.

Ethical approval Not applicable.

Consent to participate Yes, consent to participate from all the authors.

Consent to publish Yes, consent to publish from all the authors.

Open Access This article is licensed under a Creative Commons Attribution 4.0 International License, which permits use, sharing, adaptation, distribution and reproduction in any medium or format, as long as you give appropriate credit to the original author(s) and the source, provide a link to the Creative Commons licence, and indicate if changes were made. The images or other third party material in this article are included in the article's Creative Commons licence, unless indicated otherwise in a credit line to the material. If material is not included in the article's Creative Commons licence and your intended use is not permitted by statutory regulation or exceeds the permitted use, you will need to obtain permission directly from the copyright holder. To view a copy of this licence, visit http://creativecommons.org/licenses/by/4.0/.

\section{References}

1. Zhang C, Shi G, Ehmann KF (2017) Investigation of hybrid microtexture fabrication in elliptical vibration-assisted cutting. Int J Mach Tools Manuf 120:72-84. https://doi.org/10.1016/j.ijmachtools. 2017.04.009

2. Wu M, Liu J, He J, Chen X, Guo Z (2020) Fabrication of surface microstructures by mask electrolyte jet machining. Int J Mach Tools 
Manuf 148:103471. https://doi.org/10.1016/j.ijmachtools.2019. 103471

3. Zhang S, Zhou Y, Zhang H, Xiong Z, To S (2019) Advances in ultra-precision machining of micro-structured functional surfaces and their typical applications. Int J Mach Tools Manuf 142:1641. https://doi.org/10.1016/j.ijmachtools.2019.04.009

4. Costa HL, Hutchings IM (2007) Hydrodynamic lubrication of textured steel surfaces under reciprocating sliding conditions. Tribol Int 40:1227-1238. https://doi.org/10.1016/j.triboint.2007.01.014

5. Liew KW, Kok CK, Ervina Efzan MN (2016) Effect of EDM dimple geometry on friction reduction under boundary and mixed lubrication. Tribol Int 101:1-9. https://doi.org/10.1016/j.triboint. 2016.03.029

6. Vilhena LM, Ramalho A, Cavaleiro A (2017) Grooved surface texturing by electrical discharge machining (EDM) under different lubrication regimes. Lubr Sci 29:493-501. https://doi.org/10.1002/ 1s. 1383

7. Bruzzone AAG, Costa HL, Lonardo PM, Lucca DA (2008) Advances in engineered surfaces for functional performance. CIRP Ann 57:750-769. https://doi.org/10.1016/j.cirp.2008.09.003

8. Bhattacharyya B, Doloi B (2020) Chapter Four Machining processes utilizing thermal energy. Modern Machining Technology, pp 161-363. https://doi.org/10.1016/b978-0-12-812894-7.00004-9

9. Dubey AK, Yadava V (2008) Laser beam machining-a review. Int J Mach Tools Manuf 48:609-628. https://doi.org/10.1016/j. ijmachtools.2007.10.017

10. Kant K, Losic D (2013) Focused Ion Beam (FIB) Technology for Micro- and Nanoscale Fabrications. In: FIB Nanostructures. Springer, pp 1-22. https://doi.org/10.1007/978-3-319-02874-3_1

11. Krauss PR, Chou SY (1996) Sub-10 nm imprint lithography and applications. In: 1997 55th Annual Device Research Conference Digest. IEEE, pp 90-91. https://doi.org/10.1109/DRC.1997.6124

12. Luo X, Sun J, Ritchie JM, Chang W, Wang W (2011) Deterministic fabrication of nanostructures for plasmonic lens by focused ion beam. Int J Adv Manuf Technol 57:1003-1009. https://doi.org/10. 1007/s00170-011-3336-0

13. Chen W, Huo D, Hale J, Ding H (2018) Kinematics and toolworkpiece separation analysis of vibration assisted milling. Int $\mathrm{J}$ Mech Sci 136:169-178. https://doi.org/10.1016/j.ijmecsci.2017. 12.037

14. Shamoto E, Moriwaki T (1994) Study on elliptical vibration cutting. CIRP Ann 43:35-38. https://doi.org/10.1016/S0007-8506(07) 62158-1

15. Song YC, Nezu K, Park CH, Moriwaki T (2009) Tool wear control in single-crystal diamond cutting of steel by using the ultraintermittent cutting method. Int J Mach Tools Manuf 49:339-343. https://doi.org/10.1016/j.ijmachtools.2008.10.014

16. Zhang SJ, To S, Zhang GQ (2017) Diamond tool wear in ultraprecision machining. Int J Adv Manuf Technol 88:613-641. https://doi.org/10.1007/s00170-016-8751-9

17. Hosseinabadi HN, Sajjady SA, Amini S (2018) Creating micro textured surfaces for the improvement of surface wettability through ultrasonic vibration assisted turning. Int J Adv Manuf Technol 96:2825-2839. https://doi.org/10.1007/s00170-018$1580-2$

18. Liu X, Wu D, Zhang J (2018) Fabrication of micro-textured surface using feed-direction ultrasonic vibration-assisted turning. Int J Adv Manuf Technol 97:3849-3857. https://doi.org/10.1007/s00170018-2082-y

19. Gandhi R, Sebastian D, Basu S, Mann JB, Iglesias P, Saldana C (2016) Surfaces by vibration/modulation-assisted texturing for tribological applications. Int J Adv Manuf Technol 85:909-920. https://doi.org/10.1007/s00170-015-7968-3

20. Zhang J, Suzuki N, Wang Y, Shamoto E (2015) Ultra-precision nano-structure fabrication by amplitude control sculpturing method in elliptical vibration cutting. Precis Eng 39:86-99. https://oi.org/ 10.1016/j.precisioneng.2014.07.009

21. Xu S, Shimada K, Mizutani M, Kuriyagawa T (2014) Fabrication of hybrid micro/nano-textured surfaces using rotary ultrasonic machining with one-point diamond tool. Int J Mach Tools Manuf 86: 12-17. https://doi.org/10.1016/j.ijmachtools.2014.06.005

22. Kim GD, Loh BG (2007) Characteristics of chip formation in micro $\mathrm{V}$-grooving using elliptical vibration cutting. J Micromechanics Microengineering 17:1458-1466. https://doi.org/10.1088/09601317/17/8/007

23. Hussein R, Sadek A, Elbestawi MA, Attia MH (2019) Elimination of delamination and burr formation using high-frequency vibrationassisted drilling of hybrid CFRP/Ti6Al4V stacked material. Int $\mathrm{J}$ Adv Manuf Technol 105:859-873. https://doi.org/10.1007/s00170019-04248-2

24. Jieqiong L, Jinguo H, Xiaoqin Z, Zhaopeng H, Mingming L (2016) Study on predictive model of cutting force and geometry parameters for oblique elliptical vibration cutting. Int J Mech Sci 117:4352. https://doi.org/10.1016/j.ijmecsci.2016.08.004

25. Guo P, Ehmann KF (2013) Development of a tertiary motion generator for elliptical vibration texturing. Precis Eng 37:364-371. https://doi.org/10.1016/j.precisioneng.2012.10.005

26. Wang J, Liao WH, Guo P (2020) Modulated ultrasonic elliptical vibration cutting for ductile-regime texturing of brittle materials with 2-D combined resonant and non-resonant vibrations. Int $\mathrm{J}$ Mech Sci 170:105347. https://doi.org/10.1016/j.ijmecsci.2019. 105347

27. Zhang J, Cui T, Ge C, Sui Y, Yang H (2016) Review of micro/nano machining by utilizing elliptical vibration cutting. Int J Mach Tools Manuf 106:109-126. https://doi.org/10.1016/j.ijmachtools.2016. 04.008

28. Yang Z, Zhu L, Zhang G, Ni C, Lin B (2020) Review of ultrasonic vibration-assisted machining in advanced materials. Int $\mathrm{J}$ Mach Tools Manuf 156:103594. https://doi.org/10.1016/j.ijmachtools. 2020.103594

29. Zheng L, Chen W, Huo D (2020) Review of vibration devices for vibration-assisted machining. Int J Adv Manuf Technol 108:16311651. https://doi.org/10.1007/s00170-020-05483-8

30. Brehl DE, Dow TA (2008) Review of vibration-assisted machining. Precis Eng 32:153-172. https://doi.org/10.1016/j.precisioneng. 2007.08.003

31. Li G, Che L, Wang B, et al (2014) Experimental study on elliptical vibration cutting for optical microstructures. 7th Int Symp Adv Opt Manuf Test Technol Des Manuf Test Micro- Nano-Optical Devices Syst 9283:928304. https://doi.org/10.1117/12.2069915

32. Zhang C, Ehmann K, Li Y (2015) Analysis of cutting forces in the ultrasonic elliptical vibration-assisted micro-groove turning process. Int J Adv Manuf Technol 78:139-152. https://doi.org/10. 1007/s00170-014-6628-3

33. Loh BG, Kim GD (2012) Correcting distortion and rotation direction of an elliptical trajectory in elliptical vibration cutting by modulating phase and relative magnitude of the sinusoidal excitation voltages. Proc Inst Mech Eng Part B J Eng Manuf 226:813-823. https://doi.org/10.1177/0954405411431375

34. Hong MS, Ehmann KF (1995) Generation of engineered surfaces by the surface-shaping system. Int J Mach Tools Manuf 35:12691290. https://doi.org/10.1016/0890-6955(94)00114-Y

35. Heamawatanachai S, Bamberg E (2009) Design and characterization of a PZT driven micromachining tool based on single-point tool tip geometry. Precis Eng 33:387-394. https://doi.org/10. 1016/j.precisioneng.2008.10.006

36. Le Zhu W, Zhu Z, He Y et al (2017) Development of a novel 2-D vibration-assisted compliant cutting system for surface texturing. IEEE/ASME Trans Mechatronics 22:1796-1806. https://doi.org/ 10.1109/TMECH.2017.2693996 
37. Yuan Y, Zhang D, Jing X, Zhu H, Zhu WL, Cao J, Ehmann KF (2019) Fabrication of hierarchical freeform surfaces by 2D compliant vibration-assisted cutting. Int J Mech Sci 152:454-464. https:// doi.org/10.1016/j.ijmecsci.2018.12.051

38. Ahn J-H, Lim H-S, Son S-M (1999) Improvement of micromachining accuracy by 2 -dimensional vibration cutting. In: Proc ASPE. pp. $150-153$

39. Han J, Lin J, Li Z, Lu M, Zhang J (2019) Design and computational optimization of elliptical vibration-assisted cutting system with a novel flexure structure. IEEE Trans Ind Electron 66:1151-1161. https://doi.org/10.1109/TIE.2018.2835425

40. Negishi N (2003) Elliptical vibration assisted machining with single crystal diamond tools. MS Diss North Carolina State Univ

41. Cerniway M (2001) Elliptical diamond milling: kinematics, force and tool wear. MS Diss North Carolina State Univ

42. Wang J, Du H, Gao S et al (2019) An ultrafast 2-D non-resonant cutting tool for texturing micro-structured surfaces. J Manuf Process 48:86-97. https://doi.org/10.1016/j.jmapro.2019.10.023

43. Guo P, Lu Y, Ehmann KF, Cao J (2014) Generation of hierarchical micro-structures for anisotropic wetting by elliptical vibration cutting. CIRP Ann 63:553-556. https://doi.org/10.1016/j.cirp.2014. 03.048

44. Paros JM, Weisbord L (1965) How to design flexure hinges. Mach Des 37:151-156

45. Lin J, Han J, Lu M, Yu B, Gu Y (2017) Design, analysis and testing of a new piezoelectric tool actuator for elliptical vibration turning. Smart Mater Struct 26:85008. https://doi.org/10.1088/1361-665x/ aa71f0
46. Zhou M, Eow YT, Ngoi BKA, Lim EN (2003) Vibration-assisted precision machining of steel with PCD tools. Mater Manuf Process 18:825-834. https://doi.org/10.1081/AMP-120024978

47. Chen W, Zheng L, Teng X, Yang K, Huo D (2018) Cutting mechanism investigation in vibration-assisted machining. Nanomanufacturing Metrol 1:268-276

48. Chen K, Si C, Guo P (2017) Design of a high bandwidth nonresonant tertiary motion generator for elliptical vibration texturing. $\mathrm{J}$ Micro Nano-Manufacturing 5:11008. https://doi.org/10.1115/1. 4035473

49. Yong YK, Lu T-F, Handley DC (2008) Review of circular flexure hinge design equations and derivation of empirical formulations. Precis Eng 32:63-70. https://doi.org/10.1016/j.precisioneng.2007. 05.002

50. Raghavendra MRA, Kumar AS, Jagdish BN (2010) Design and analysis of flexure-hinge parameter in microgripper. Int J Adv Manuf Technol 49:1185-1193. https://doi.org/10.1007/s00170009-2478-9

51. Yong YK, Lu TF (2009) Comparison of circular flexure hinge design equations and the derivation of empirical stiffness formulations. IEEE/ASME Int Conf Adv Intell Mechatronics, AIM:510 515. https://doi.org/10.1109/AIM.2009.5229961

52. Brocato BC (2004) Micromachining using EVAM (elliptical vibration assisted machining). MS Diss North Carolina State Univ

53. Negishi $\mathrm{N}$ (2003) Elliptical vibration assisted machining with single crystal diamond tools. MS Diss North Carolina State Univ

Publisher's note Springer Nature remains neutral with regard to jurisdictional claims in published maps and institutional affiliations. 